\title{
Von Jesus zum Neuen Testament
}

\author{
Studien zur urchristlichen Theologiegeschichte und zur Entstehung des \\ neutestamentlichen Kanons
}

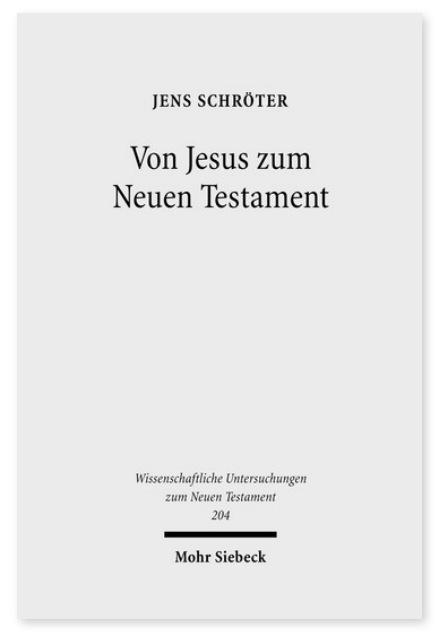

2007; unveränderte Studienausgabe; 2008. IX, 441 Seiten. WUNT I 204

ISBN 978-3-16-151493-7

DOI 10.1628/978-3-16-151493-7

eBook PDF $64,00 €$
Jens Schröter befasst sich in den vorliegenden Studien mit vier Themenkreisen. Im ersten Teil geht es um die methodischen Voraussetzungen einer Rekonstruktion der urchristlichen Theologiegeschichte. Dabei werden in Anknüpfung an Johann Gustav Droysen, den Begründer der neuzeitlichen Historik, aktuelle Diskurse aus der Geschichtstheorie aufgenommen. Der zweite Teil konkretisiert die dabei zutage tretenden Aspekte an drei zentralen Bereichen des Urchristentums: der frühen Jesusüberlieferung, der Theologie des Paulus sowie dem Geschichtsentwurf der Apostelgeschichte. Besonderes Augenmerk liegt dabei auf der Einordnung der jesuanischen Wortüberlieferung in die urchristliche Überlieferungsgeschichte, dem Galaterbrief als einem Zeugnis für die Suche des Paulus nach der »Einheit des Evangeliums« sowie auf demjenigen geschichtstheologischen Modell, in dem Jesus und Paulus zum ersten Mal miteinander verbunden wurden. Der dritte Teil thematisiert die Entwicklung von den einzelnen theologischen Entwürfen des Urchristentums hin zum Neuen Testament. Im 'Neuen Testament', mit dem sich das frühe Christentum einen 'Kanon' verbindlicher Texte schuf, sind Schriften verschiedenen literarischen und theologischen Charakters vereinigt worden. Dies führt schließlich zu der Frage, wie aus heutiger Sicht eine diese Schriften übergreifende Interpretation des Gesamtcorpus - also eine 'Theologie des Neuen Testaments' - zu konzipieren wäre. Diesem Thema wendet sich der Autor abschließend zu.

Jens Schröter Geboren 1961; 1992 Promotion; 1996 Habilitation; Professur für Exegese und Theologie des Neuen Testaments sowie die antiken christlichen Apokryphen an der Theologischen Fakultät der Humboldt-Universität zu Berlin. https://orcid.org/0000-0001-7878-2709
Jetzt bestellen:

https://mohrsiebeck.com/buch/von-jesus-zum-neuen-testament-9783161514937?no_cache=1

order@mohrsiebeck.com

Telefon: +49 (0)7071-923-17

Telefax: $+49(0) 7071-51104$ 